\title{
Maternal Vulnerabilities and Disparities in Availability of Antenatal Care Content in Kenya: Analysis of KDHS 2008/9
}

\author{
James Ouma ${ }^{1, *}$, Collins Otieno Asweto ${ }^{2}$ \\ ${ }^{1}$ Department of Environmental Health, University of Kabianga, Kericho, Kenya \\ ${ }^{2}$ School of Public Health, Maseno University, Kisumu, Kenya \\ *Corresponding author: j.ouma@kabianga.ac.ke
}

\begin{abstract}
Background: ANC provides the opportunity to detect and treat anomalies of pregnancy and access to preventive maternal and child healthcare. However, detailed information about the actual quality and content of ANC in practice is scanty, especially in developing countries. We analyzed the pattern and content of antenatal care service in Kenya in order to assess the quality of ANC. Methods: We used data from the 2008/9 KDHS, a nationally representative survey of women aged 15-49 years in Kenya. Proportion was used for description purpose while association was determined by bivariate and multivariate analysis in which odds ratio with a $95 \%$ confidence interval values were calculated. Results: About 50.9\% of women sought ANC services either in health centers or dispensaries but these lower level health facilities had more content gaps. Multivariate analysis indicated that maternal age, regional residence, urban residence, wealth index, education and the media influenced ANC initiation and at least 4 ANC visits. There was a coverage gap existing in terms of iron-folate supplementation (66.1\%), tetanus toxoid (66.5\%), presumptive/preventive treatment for malaria with SP $(38.7 \%)$ and education on pregnancy complication $(44.3 \%)$. Nearly a third of women missed the screening for complication during pregnancy. Conclusion: Disparities exist in provision of ANC components, by type of facility attended, rural-urban and low versus higher income biases. Consequently vulnerable women attending ANC miss important care including screening for complication during pregnancy and labor. Efforts should be designed to improve on supplies to government health centers and dispensaries. Well stocked outreach village clinics with the requirements of a comprehensive antenatal care resource allocation should be used to eliminate service disparities. Government policy should help to increase media penetration amongst the masses and sensitize mothers on the importance of ANC.
\end{abstract}

Keywords: antenatal care, health facility, ANC components, Kenya

Cite This Article: James Ouma, and Collins Otieno Asweto, "Maternal Vulnerabilities and Disparities in Availability of Antenatal Care Content in Kenya: Analysis of KDHS 2008/9." American Journal of Public Health Research, vol. 5, no. 4 (2017): 115-123. doi: 10.12691/ajphr-5-4-4.

\section{Introduction}

Approximately 800 women die every day globally from preventable causes related to pregnancy and childbirth [1]. In 2010, about 287,000 women died worldwide during and following pregnancy and childbirth $[1,2]$. Though this is a decline of $47 \%$ from the 1990 level, it is still far from the 2015 Millennium Development Goal (MDG). The fifth MDG calls for a reduction in the maternal mortality ratio by $75 \%$ between 1990 and 2015. The key indicators to measure this goal are the proportion of pregnant mothers who received ANC and the proportion of births attended by skilled delivery attendants $[1,3]$.

Despite proven interventions that could prevent death or disability during pregnancy and childbirth, maternal mortality remains a major burden in many developing countries. Maternal mortality continues to be a major challenge in Africa and the maternal mortality disparity between developing and developed countries is very high. The maternal mortality ratio (MMR) in developing regions is 15 times higher than in the developed regions $[1,3,4]$ and Sub Saharan African countries have the highest MMR in the world with an average of 500 maternal deaths per 100,000 live births, accounting for half of the world's total maternal deaths [1,2,5], Kenya having 488 maternal deaths per 100,000 live births [6].

Most women die because they give birth without the attendance of a skilled health worker [2,5]. The antenatal period is critically important for reaching women with interventions and information that promote health, wellbeing and survival of mothers as well as their babies. The coverage of at least one visit with a doctor, nurse or midwife has progressively increased in developing regions $[1,2]$. Antenatal care (ANC) coverage is a success story in Africa, since over two-thirds of pregnant women (69 percent) have at least one ANC contact in Sub Saharan Africa, compared 54\% in Asia [7]. Although attendance at ANC is encouraging, worrying gaps exist in provision, 
and coverage statistics are usually based on women who have only one ANC visit, whereas four visits are recommended, and ANC quality varies $[8,9,10]$. ANC has the potential to contribute to reducing maternal and child morbidity and mortality [11].

Recent studies have challenged the potential of ANC to reduce maternal mortality [12,13]. Both quality and coverage are essential to maximize impact. Although the current rate of ANC uptake is encouraging, detailed information about the actual quality and effectiveness of ANC in practice is scant. This is largely because the packages vary so much from place to place in terms of components, timing, frequency of visits, and provider [14]. WHO recommends a new model of ANC for women with uncomplicated pregnancy in developing countries, with at least four visits with compulsory measurement of blood pressure, testing of urine and blood tests and optional weight and height measurement at each visit [15].

However, to achieve the full life-saving potential that ANC promises for women and babies, four visits providing essential evidence based interventions are required. Essential interventions in ANC include identification and management of obstetric complications such as preeclampsia, tetanus toxoid immunization, intermittent preventive treatment for malaria during pregnancy (IPTp), and identification and management of infections including HIV, syphilis and other sexually transmitted infections (STIs) [16]. ANC provides the opportunity to detect and treat anomalies of pregnancy and to deliver preventive health services [16]. To fully benefit from these interventions, it is important that women start ANC early on in their pregnancy. An analysis of Demographic and Health Surveys (DHS) from 45 developing countries showed that women in sub-Saharan Africa start antenatal care considerably later than women from other regions [17]. Similarly, other studies reported late ANC enrolment after more than five months of gestation in sub-Saharan African countries [18,19,20]. Many of these opportunities continue to be missed, even though over two-thirds of pregnant women receive at least one antenatal visit [7].

In Kenya the percentage of pregnant women attending ANC visits has been high-88 percent in the 2003 KDHS [21] and 92 percent in the 2008-09 KDHS [6]. Although the current rate of ANC uptake is encouraging, detailed information about the actual quality and effectiveness of ANC in practice is scant. To the best of my knowledge, this might be the first attempt to address the adequacy of ANC with a combination of the number of visits, the initiation of visit and the content of ANC using KDHS data. The objective of this paper was to analyze the pattern and content of antenatal care service in Kenya. The result should lead to policy recommendations to improve maternal health care in Kenya.

\section{Methodology}

\subsection{Source of Data}

This study used data from the 2008/9 Kenya Demographic and Health Survey (KDHS), this is a nationally representative survey of 8,444 women aged 15-49 years. The KDHS provides data on demographic and health indicators to promote studies on population, health, and nutrition of women and children in developing countries. The survey data was downloaded from Measure DHS website after data use permission was guaranteed. The 2008/9 KDHS is part of the worldwide MEASURE DHS project which was funded by the United States Agency for International Development (USAID) and was implemented by the Kenya National Bureau of Statistics. This study used data on births that occurred in the five years preceding the survey period, and was restricted to the most recent births to 4165 women aged $15-49$ at the time of birth. Information on the most recent birth was used as it was assumed that the woman could vividly remember events during that pregnancy.

\subsection{Sampling Procedure}

Multi-stage stratified design sampling was used to draw sample for 2008/9 KDHS, in this design, a two staged sampling method was employed; a) selection of clusters from a national master sample; and b) sampling of households from a list of all households in the sampled clusters [6]. This was to allow for separate estimates of key indicators for each of the eight provinces in the country, and for urban and rural areas separately [6]. A total of 9,936 households were selected in the sample, of which 9,268 were occupied at the time of fieldwork and thus eligible for interviews [6]. Of the eligible households, 9,057 households were successfully interviewed, yielding a response rate of 98 percent. From the households interviewed, 8,767 women were found to be eligible and 8,444 were interviewed, giving a response rate of 96 percent [6].

\subsection{Data Collection Procedures}

A structured and pre-tested questionnaire was used as a tool for data collection. The questionnaire was developed in English and then translated into local languages. The questionnaire was developed based on standard DHS survey questionnaires. Structured interview schedules were performed by trained interviewers. In order to maintain the quality of data to be collected, interviewers were trained, a pretest was performed before the actual data collection, frequent supervision was performed during data collection and interviews were performed using local languages [6].

\subsection{Measurement of Variables}

\subsubsection{Dependent Variable}

Antenatal care (ANC) was the main outcome of interest in which we look at number of ANC visits, the initiation of ANC visits and the content of ANC. Dichotomous dependent variables were created from this ANC specific questions, namely: (a) The number of antenatal care visits the women had during their last pregnancy; $1=$ had four and more visits; $0=$ had less than four visits. (b) The time women initiated their antenatal care visit; $1=$ at first trimester; $0=$ at second and third trimester. (c) The ANC contents had ten parts (i) Height measured $1=$ yes, $0=$ no; (ii) Weight measured $1=y e s, 0=$ no; (iii) Blood pressure taken $1=y e s, 0=$ no; (iv) Urine sample taken $1=y e s, 0=$ no; (v) Blood sample taken $1=y e s, 0=$ no; (vi) Told about 
pregnancy complication; $1=y e s, 0=$ no; (vii) Told where to go in case of pregnancy complication $1=y e s, 0=$ no; (viii) Iron tablet given $1=y e s, 0=$ no; (ix) $S P$ given $1=y e s, 0=$ no; (x) Tetanus injection given before birth $1=y e s, 0=$ no.

\subsubsection{Independent Variable}

The age of the women at the time of survey included the date of birth. We used age categorized in cohort of five years; $15-19,20-24,25-29,30-34,35-39,40-44$, and 4549. Parity was categorized according to the number of children a woman had, which was classified into three categories: those who had one child; those who had 2-3 children; those who had 4 and above. Maternal education was categorized into four classes namely; no education, primary, secondary and higher education. These categories were made to allow for nonlinearity in the effects of education on utilization behavior and correspondent to primary, secondary and higher education as is currently prevalent in KDHS [6].

Women were also categorized as per the region they reside on; Kenya has eight regions known as provinces namely Nairobi, Coast, Eastern, Rift valley, North Eastern, Nyanza, Western, and Central. Residence was also further considered as urban and rural. Frequency of newspaper reading, listening to radio, and watching TV was also measured, in order to determine how the frequency of using these media influences ANC use, they were categorized as: not at all, less than once a week, at least once a week and almost every day to all the three form of media. For the purpose of this study, the resulting continuous variable (wealth index) was recoded with categories labeled poorest, poor, middle, rich and richest. Type of health facility were also categorized as private health facility, faith based health facility, government hospital, government health center and government dispensary and others.

\subsection{Data Analysis Procedures}

Analysis was done using SPSS version 20.0. Frequencies were first determined in which proportions were estimated. Bivariate and multivariate analysis techniques were used during analysis. The association between dependent and independent variables was measured by means of odds ratio with a $95 \%$ confidence interval. Variables that show a statistically significant association $(\mathrm{p}<0.05)$ at bivariate level were further analyzed at multivariate level by logistic regression. This is because these variables showed an influence on the outcome variable and there is a need to identify whether each has been confounded by another variable or not. The adjusted odds ratio (AOR) was used to determine the presence of association between the dependent and independent variables for which $95 \%$ CI was determined.

\section{Results}

\subsection{Characteristics of Women}

A total of 4,165 women aged 15 to 49 years of age who had at least one birth five years before the survey were included. Mean age of the respondents is $28.59 \pm 7.04$ years, minimum age 15 and maximum age being 49 . Table 1 shows that majority $(51.8 \%)$ of women was in age group $20-29$ years. Nyanza and Rift Valley had majority of women in the study, both at $17 \%$ each. About $72.8 \%$ of women were rural residents and more than half $(56.3 \%)$ of women had primary education. Almost two third (65.0\%) of women do not read news paper or magazine at all, while more than a half $(54.8 \%)$ of them listen to radio almost every day, and only a fifth $(20.5 \%)$ watch television almost every day. About a quarter (24.8\%) of women was in the poorest category of wealth index and about $24.1 \%$ were in the richest category.

Table 1. Distribution of women characteristics

\begin{tabular}{|c|c|c|}
\hline Age & Frequency & Percent \\
\hline $15-19$ & 290 & 7.0 \\
\hline $20-24$ & 1093 & 26.2 \\
\hline $25-29$ & 1067 & 25.6 \\
\hline $30-34$ & 823 & 19.8 \\
\hline $35-39$ & 539 & 12.9 \\
\hline $40-44$ & 253 & 6.1 \\
\hline $45-49$ & 100 & 2.4 \\
\hline \multicolumn{3}{|l|}{ Parity } \\
\hline 1 & 854 & 20.5 \\
\hline $2-3$ & 1707 & 41.0 \\
\hline$>3$ & 1604 & 38.5 \\
\hline \multicolumn{3}{|l|}{ Region } \\
\hline Nairobi & 350 & 8.4 \\
\hline Central & 414 & 9.9 \\
\hline Coast & 605 & 14.5 \\
\hline Eastern & 550 & 13.2 \\
\hline Nyanza & 710 & 17.0 \\
\hline Rift Valley & 707 & 17.0 \\
\hline Western & 515 & 12.4 \\
\hline Northeastern & 314 & 7.5 \\
\hline \multicolumn{3}{|c|}{ Type of place of residence } \\
\hline Urban & 1133 & 27.2 \\
\hline Rural & 3032 & 72.8 \\
\hline \multicolumn{3}{|l|}{ Educational attainment } \\
\hline No education & 751 & 18.0 \\
\hline Primary & 2342 & 56.2 \\
\hline Secondary & 804 & 19.3 \\
\hline Higher & 268 & 6.4 \\
\hline \multicolumn{3}{|c|}{ Frequency of reading news paper } \\
\hline Not at all & 2704 & 65.0 \\
\hline Less than once a week & 742 & 17.8 \\
\hline At least once a week & 550 & 13.2 \\
\hline Almost everyday & 164 & 3.9 \\
\hline \multicolumn{3}{|c|}{ Frequency of listening to radio } \\
\hline Not at all & 859 & 20.6 \\
\hline Less than once a week & 368 & 8.8 \\
\hline At least once a week & 653 & 15.7 \\
\hline Almost everyday & 2283 & 54.8 \\
\hline \multicolumn{3}{|c|}{ Frequency of Watching TV } \\
\hline Not at all & 2564 & 61.6 \\
\hline Less than once a week & 426 & 10.2 \\
\hline At least once a week & 320 & 7.7 \\
\hline Almost everyday & 855 & 20.5 \\
\hline \multicolumn{3}{|l|}{ Wealth Index } \\
\hline Poorest & 1032 & 24.8 \\
\hline Poorer & 698 & 16.8 \\
\hline Middle & 684 & 16.4 \\
\hline Richer & 746 & 17.9 \\
\hline Richest & 1005 & 24.1 \\
\hline
\end{tabular}




\subsection{Association between ANC 4+, Early ANC Initiation and Women Characteristics}

Table 2 reveals that younger women were twice more likely to have early ANC visit compared to older women, 15-19 years had AOR= $2.08(1.32-3.3), 20-24$ years had AOR $=1.85(1.16-2.94)$ and $25-29$ years had AOR = $2.13(1.32-3.33)$. Parity was also found to influence both early ANC initiation and at least having 4 ANC visits. As the number of children a woman has decreases, utilization of ANC becomes more likely (Table 2). Only three regions of women's residence showed an association with early initiation of ANC visit. Nairobi, Coast and Nyanza were more likely to have early ANC initiation compared to North eastern province with AOR $=1.74(1.06-2.85)$, $\mathrm{AOR}=1.76(1.07$ - 2.89) and $\mathrm{AOR}=1.62(1.02$ - 2.57) respectively. On the other hand urban residence also showed an association with both ANC 4 plus and early ANC initiation where urban women were AOR $=1.41$ (1.17 - 1.69) more likely to have 4 plus ANC visits and $\mathrm{AOR}=1.53(1.20-1.95)$ times more likely to initiate ANC visit at first trimester compared to the rural women.

Table 2. Association between early ANC initiation, $\geq 4 \mathrm{ANC}$ visits and women characteristics

\begin{tabular}{|c|c|c|}
\hline & $\begin{array}{c}\text { Early ANC Initiation } \\
\text { AOR (95.0\% C.I.) }\end{array}$ & $\begin{array}{c}\geq 4 \text { ANC visits } \\
\text { AOR (95.0\% C.I.) }\end{array}$ \\
\hline \multicolumn{3}{|l|}{ Age } \\
\hline $44-49$ & 1 & 1 \\
\hline $15-19$ & $2.08(1.32-3.33) * * *$ & $0.75(0.42-1.33)$ \\
\hline $20-24$ & $1.85(1.16-2.94) * * *$ & $1.08(0.63-1.85)$ \\
\hline $25-29$ & $2.13(1.32-3.33) * * *$ & $1.22(0.71-2.09)$ \\
\hline $30-34$ & $1.67(0.99-2.78)$ & $1.55(0.90-2.67)$ \\
\hline $35-39$ & $1.41(0.76-2.56)$ & $1.39(0.80-2.42)$ \\
\hline $40-44$ & $1.25(0.55-2.86)$ & $1.22(0.67-2.23)$ \\
\hline \multicolumn{3}{|l|}{ Parity } \\
\hline 1 & $1.96(1.54-2.51) * * *$ & $1.40(1.17-1.68) * * *$ \\
\hline $2-3$ & $1.73(1.40-2.15) * * *$ & $1.28(1.10-1.48) * * *$ \\
\hline$>3$ & 1 & 1 \\
\hline \multicolumn{3}{|l|}{ Region } \\
\hline Northeastern & 1 & 1 \\
\hline Nairobi & $1.74(1.06-2.85) * * *$ & $1.20(0.55-2.62)$ \\
\hline Central & $1.15(0.71-1.86)$ & $0.69(0.31-1.54)$ \\
\hline Coast & $1.76(1.07-2.89) * * *$ & $0.60(0.27-1.31)$ \\
\hline Eastern & $1.30(0.80-2.11)$ & $0.49(0.22-1.07)$ \\
\hline Nyanza & $1.62(1.02-2.57) * * *$ & $0.54(0.24-1.19)$ \\
\hline Rift valley & $1.06(0.65-1.74)$ & $0.54(0.25-1.20)$ \\
\hline Western & $2.17(0.44-3.14)$ & $0.53(0.24-1.18)$ \\
\hline \multicolumn{3}{|l|}{ Residence } \\
\hline Rural & 1 & 1 \\
\hline Urban & $1.53(1.20-1.95) * * *$ & $1.41(1.17-1.69) * * *$ \\
\hline \multicolumn{3}{|l|}{ Wealth Index } \\
\hline Poorest & 1 & 1 \\
\hline Poorer & $1.04(0.73-1.47)$ & $0.95(0.76-1.19)$ \\
\hline Middle & $0.97(0.68-1.40)$ & $1.10(0.88-1.39)$ \\
\hline Richer & $1.89(1.24-2.69) * * *$ & 1. $60(1.27-2.01) * * *$ \\
\hline Richest & $2.35(1.64-3.04) * * *$ & $1.82(1.45-2.29) * * *$ \\
\hline \multicolumn{3}{|l|}{ Education Attainment } \\
\hline No education & 1 & 1 \\
\hline Primary education & $1.17(0.75-1.81)$ & $0.90(0.67-1.22)$ \\
\hline Secondary education & $1.28(0.76-2.14)$ & $1.37(0.96-1.96)$ \\
\hline Higher & $3.18(1.81-5.60) * * *$ & $4.02(2.47-6.55) * * *$ \\
\hline \multicolumn{3}{|c|}{ Frequency of reading news paper } \\
\hline Not at all & 1 & 1 \\
\hline Less than once a week & $1.07(0.81-1.42)$ & $1.13(0.93-1.38)$ \\
\hline At least once a week & $1.33(0.98-1.81)$ & $1.40(1.10-1.79) * * *$ \\
\hline Almost everyday & $2.75(1.81-4.19) * * *$ & $1.64(1.28-1.97) * * *$ \\
\hline \multicolumn{3}{|c|}{ Frequency of listening to radio } \\
\hline Not at all & 1 & 1 \\
\hline Less than once a week & $1.04(0.69-1.58)$ & $0.77(0.58-1.04)$ \\
\hline At least once a week & $0.83(0.58-1.20)$ & $0.87(0.68-1.13)$ \\
\hline Almost everyday & $1.54(1.14-1.94) * * *$ & $1.00(0.80-1.26)$ \\
\hline \multicolumn{3}{|c|}{ Frequency of Watching TV } \\
\hline Not at all & 1 & 1 \\
\hline Less than once a week & $0.94(0.66-1.33)$ & $1.23(0.97-1.56)$ \\
\hline At least once a week & $1.85(1.58-2.27) * * *$ & $1.30(1.08-1.71) * * *$ \\
\hline Almost everyday & $2.20(1.69-2.60) * * *$ & $1.58(1.10-1.74) * * *$ \\
\hline
\end{tabular}


The family wealth index had a positive association with 4 plus ANC visit and early ANC initiation. Women coming from richer and richest families were almost twice more likely to have 4 plus ANC visits with $\mathrm{AOR}=1.60 ; 95 \%$ $\mathrm{CI}=(1.27-2.01)$ and $\mathrm{AOR}=1.82 ; 95 \% \mathrm{CI}=(1.45-2.29)$ respectively. This was similarly observed on early initiation of ANC visits, where the richer family had AOR $=1.89$; 95\% CI $=(1.24-2.69)$ and Richest had AOR $=2.35 ; 95 \%$ $\mathrm{CI}=(1.64-3.04)$. Women with higher education were four times more likely to have 4 plus $\mathrm{ANC}$ ( $\mathrm{AOR}=4.02$; $95 \%=2.47-6.55)$ and three times likely to initiate ANC visit at first trimester $(\mathrm{AOR}=3.18 ; 95 \% \mathrm{CI} 1.81-5.60)$ compared to those with no education. Media also tend to have a significant influence where frequency of reading the newspaper or magazine tend to increase the likelihood having 4 plus ANC visits, women who read once a week had $\mathrm{AOR}=1.40 ; 95 \% \mathrm{CI}=(1.10-1.79)$ while women who read almost every day had AOR $=1.54 ; 95 \% \mathrm{CI}=(1.28$ 1.97). It has also been observed that women who read newspaper or magazine almost every day were almost three times more likely to initiate early $\mathrm{ANC}$ visits $(\mathrm{AOR}=2.75$;
95\% $\mathrm{CI}=1.81-4.19)$ compared to those not reading. Women who listen to radio almost every day were 1.5 times more likely to have early initiation of ANC (AOR $=1.54 ; 95 \%$ $\mathrm{CI}=1.14-1.94)$ compared to those who do not listen at all. Women who watch TV at least once a week were 1.3 times more likely to have 4 plus $\mathrm{ANC}(\mathrm{AOR}=1.30 ; 95 \% \mathrm{CI}=$ 1.08-1.71) and twice more likely to have early initiation of ANC $(\mathrm{AOR}=1.85 ; 95 \% \mathrm{CI}=1.58-2.27)$ compared to those who don't watch at all, while those who watch almost every day were 1.6 times more likely to have 4 plus ANC $(\mathrm{AOR}=1.58 ; 95 \% \mathrm{CI}=1.10-1.74)$ and 2.2 times more likely to have early initiation of ANC (AOR $=2.20 ; 95 \%$ CI $1.69-2.60)$ compared to those who don't watch at all.

\subsection{Place of ANC Service}

Figure 1 shows that majority (32.5\%) of women sought ANC services in the government hospital, while government health center and dispensary was $50.9 \%$. About $16 \%$ of women sought ANC service in private and faith based health facilities.

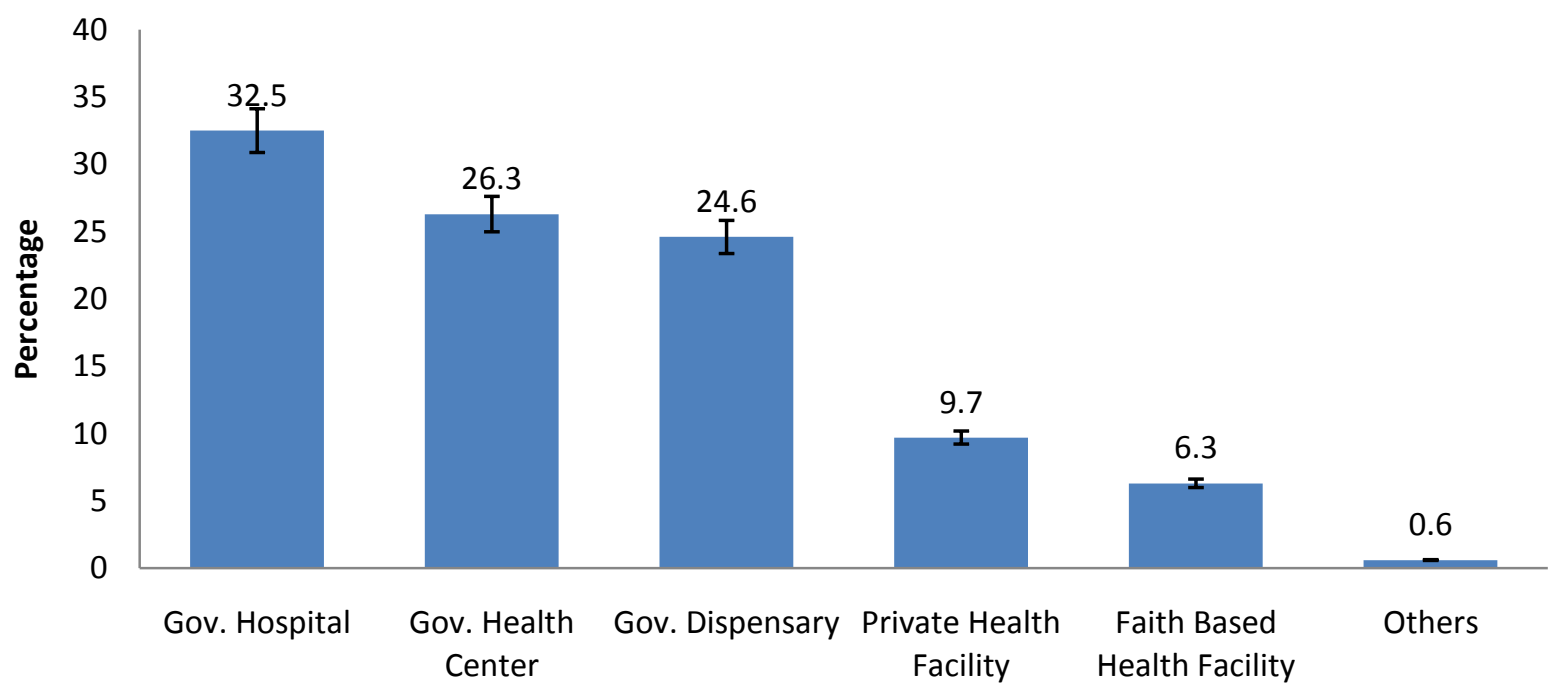

Type of Health facility

Figure 1. Place of seeking ANC service by the women

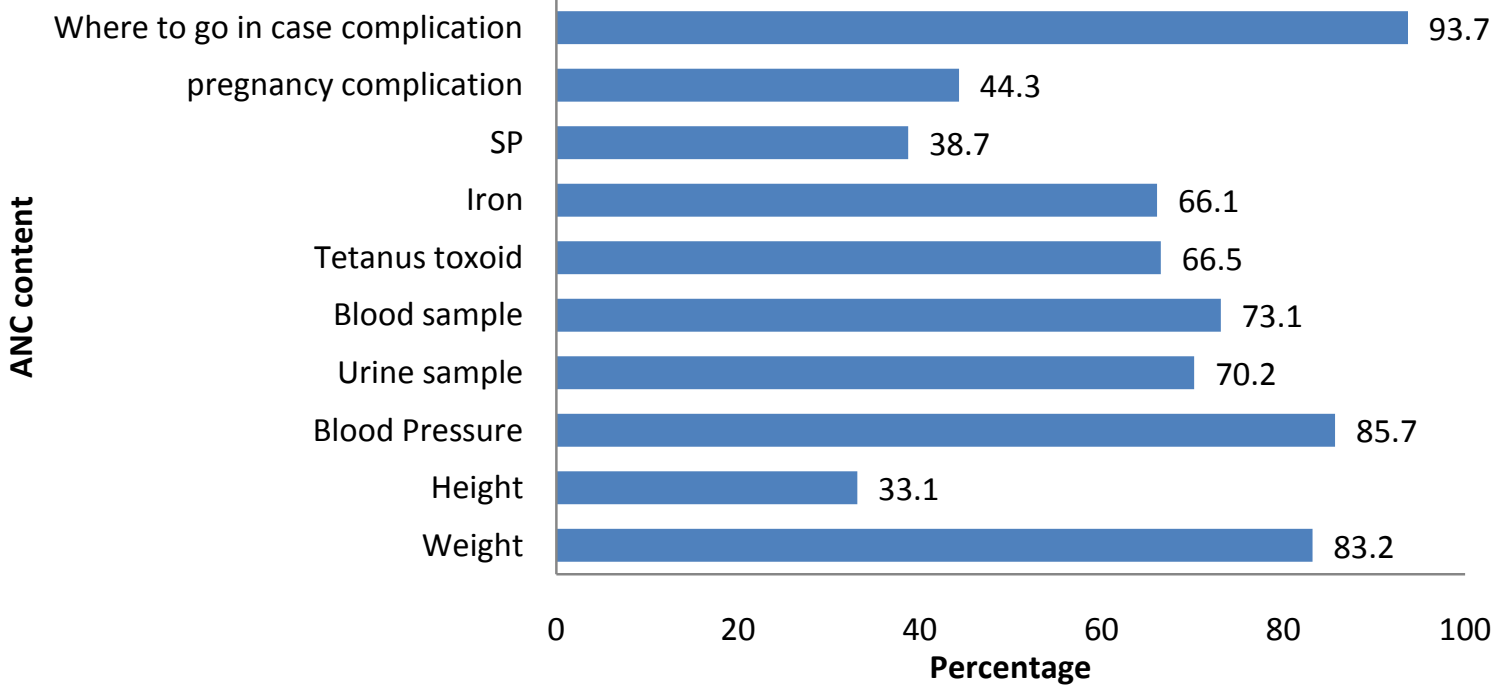

Figure 2. Percentage of ANC service by content 


\subsection{Content of ANC services}

As shown in the Figure 2, nearly all (93.7\%) respondents were advised on where to go in case of complication, however only $44.3 \%$ were told about pregnancy complications. There were marked coverage gaps for each of these elements of care, ranging from $33.1 \%$ to $85.7 \%$. Some of the preventive measures such as iron-folate supplementation $(66.1 \%)$, tetanus toxoid $(66.5 \%)$ and presumptive/preventive treatment for malaria with SP $(38.7 \%)$ showed coverage gap existing. On average, nearly $30 \%$ missed the screening of complication during pregnancy as this shown by proportion having blood sample taken $(73.1 \%)$, urine sample taken $(70.2 \%)$ and blood pressure $(85.7 \%)$.

Content of ANC services was assessed in all the level of health facilities by determining the ten ANC services provided during the pregnancy. Table 3 shows that women seeking ANC service in the private health facility (AOR $=2.31 ; 95 \% \mathrm{CI}=1.28-3.38)$, Faith based health facility $(\mathrm{AOR}=1.48 ; 95 \% \mathrm{CI}=1.07-2.26)$ and government hospital $(\mathrm{AOR}=1.44 ; 95 \% \mathrm{CI}=1.02-2.03$ ) were more likely to have their height measured compared to women who visit the dispensary. In terms of weight measurement, both private health facility ( $\mathrm{AOR}=9.67 ; 95 \% \mathrm{CI}=5.10-18.34$ ), Faith based health facility $(\mathrm{AOR}=15.67 ; 95 \% \mathrm{CI}=6.91$ 35.53), government hospital ( $\mathrm{AOR}=20.31$; 95\% $\mathrm{CI}=$ 11.88-34.73) and health center $(\mathrm{AOR}=13.40$; $95 \% \mathrm{CI}=$ 7.92-22.69) were more likely to have their height measured compared to women who visit the dispensary.
Blood pressure was more likely to be measured among women attending private hospital (AOR $=8.672 ; 95 \%$ $\mathrm{CI}=4.85-15.51$ ), faith based health facility ( $\mathrm{AOR}=10.52$; 95\% $\mathrm{CI}=5.29-20.93)$, government hospital $(\mathrm{AOR}=5.89$; 95\% $\mathrm{CI}=3.77-9.21)$ and health center $(\mathrm{AOR}=1.95 ; 95 \%$ $\mathrm{CI}=1.26-3.01)$ compared to dispensary. Taking of urine sample during ANC also showed an association with type of health facility, where women who sought ANC in private health facility ( $\mathrm{AOR}=5.86 ; 95 \% \mathrm{CI}=3.68-9.31$ ), faith based health facility ( $\mathrm{AOR}=2.59 ; 95 \% \mathrm{CI}=1.62-4.13$ ), government hospital $(\mathrm{AOR}=5.11 ; 95 \% \mathrm{CI}=3.45-7.57)$, and health center $(\mathrm{AOR}=1.82 ; 95 \% \mathrm{CI}=1.28-3.31)$ were more likely to have their urine sample taken compared to those who sought ANC service in the dispensary. Those who attended private health facility $(\mathrm{AOR}=2.04 ; 95 \%$ $\mathrm{CI}=1.40-2.96$ ), faith based health facility (AOR $=1.96$; 95\% CI=1.30-2.94), government hospital (AOR $=1.94$; 95\% CI $=1.39-2.71)$ and health center $(\mathrm{AOR}=1.40 ; 95 \%$ $\mathrm{CI}=1.08-1.97$ ) were more likely to be told about complication during pregnancy compared to those who went to dispensary, this association showed a decrease in likelihood with decrease in level of health facility. Tetanus injection also showed a similar association with level of health facility, those who were served in private health facility (AOR $=5.85 ; 95 \% \mathrm{CI}=3.23-10.62$ ), faith based health facility (AOR $=3.59 ; 95 \% \mathrm{CI}=1.62-7.96)$, government hospital ( $\mathrm{AOR}=2.54 ; 95 \% \mathrm{CI}=1.52-4.26)$ and health center (AOR $=2.50 ; 95 \% \mathrm{CI}=1.47-4.25)$ were more likely receive tetanus injection during pregnancy compared to those who were served in dispensary.

Table 3. Quality of ANC services by health facility

\begin{tabular}{|c|c|c|c|}
\hline & $\begin{array}{l}\text { Height measured } \\
\text { AOR(95\% CI })\end{array}$ & $\begin{array}{c}\text { Weight measured } \\
\text { AOR(95\% CI })\end{array}$ & $\begin{array}{c}\text { BP taken } \\
\text { AOR(95\% CI })\end{array}$ \\
\hline \multicolumn{4}{|l|}{ Level of HF } \\
\hline Private & $2.31(1.28-3.38)^{* *}$ & $9.67(5.10-18.34) * *$ & $8.672(4.85-15.51) * *$ \\
\hline $\mathrm{FBH}$ & $1.48(1.07-2.26) * *$ & $15.67(6.91-35.53) * *$ & $10.52(5.29-20.93) * *$ \\
\hline Government Hospital & $1.44(1.02-2.03) * *$ & $20.31(11.88-34.73) * *$ & $5.89(3.77-9.21) * *$ \\
\hline Gov. Health Center & $1.21(0.84-1.72)$ & $13.40(7.92-22.69) * *$ & $1.95(1.26-3.01) * *$ \\
\hline \multirow[t]{2}{*}{ Gov. Dispensary } & 1 & 1 & 1 \\
\hline & $\begin{array}{c}\text { Urine sample } \\
\operatorname{AOR}(95 \% \mathrm{CI})\end{array}$ & $\begin{array}{c}\text { Told about Complication } \\
\text { AOR(95\% CI })\end{array}$ & $\begin{array}{c}\text { Where to go in case of } \\
\text { complication } \\
\operatorname{AOR}(95 \% \mathrm{CI})\end{array}$ \\
\hline \multicolumn{4}{|l|}{ Level of HF } \\
\hline Private & $5.86(3.68-9.31) * *$ & $2.04(1.40-2.96) * *$ & $1.06(0.35-3.26)$ \\
\hline $\mathrm{FBH}$ & $2.59(1.62-4.13) * *$ & $1.96(1.30-2.94) * *$ & $4.28(0.77-23.96)$ \\
\hline Government Hospital & $5.11(3.45-7.57) * *$ & $1.94(1.39-2.71) * *$ & $1.43(0.50-4.09)$ \\
\hline Gov. Health Center & $1.82(1.28-3.31) * *$ & $1.40(1.08-1.97) * *$ & $1.22(0.41-3.36)$ \\
\hline \multirow[t]{2}{*}{ Gov. Dispensary } & 1 & 1 & 1 \\
\hline & $\begin{array}{l}\text { Iron tablets given } \\
\operatorname{AOR}(95 \% \mathrm{CI})\end{array}$ & $\begin{array}{c}\text { SP given } \\
\text { AOR(95\% CI })\end{array}$ & $\begin{array}{c}\text { Tetanus Injection } \\
\text { AOR(95\% CI })\end{array}$ \\
\hline \multicolumn{4}{|l|}{ Level of HF } \\
\hline Private & $1.12(0.74-1.69)$ & $2.63(1.42-4.94) * *$ & $5.85(3.23-10.62) * *$ \\
\hline FBH & $0.57(0.36-0.89)$ & $1.65(1.18-2.62) * *$ & $3.59(1.62-7.96) * *$ \\
\hline Government Hospital & $1.37(0.95-1.99)$ & $1.37(1.07-1.94) * *$ & $2.54(1.52-4.26) * *$ \\
\hline Gov. Health Center & $2.00(1.37-2.94) * *$ & $1.22(0.93-1.90)$ & $2.50(1.47-4.25) * *$ \\
\hline Gov. Dispensary & 1 & 1 & 1 \\
\hline
\end{tabular}




\section{Discussion}

The purpose of this paper was to analyze the pattern and adequacy of antenatal care use in Kenya using KDHS of 2008/2009. Specifically, we investigated the timing of the first antenatal clinic visit, number of antennal clinic visits and content of antenatal care provided at each level of health facility. Antenatal care is considered a key entry point for pregnant women to receive a broad range of health promotion and disease preventive services [22]. The study shows that both ANC initiation and having at least 4 ANC visits varies with maternal age, region of residence, urban residence, wealth index, education and the three forms of media.

We reveal that younger women had higher probability of initiating ANC visit at 1st trimester compared to older women. The possible explanation might be that young women with their first pregnancy and childbirth are more careful about their pregnancy and therefore require seeking institutional care than older women, who tend to trust traditional birth attendants due to previous experiences they had. Young women may also be likely to be educated than older women. This finding concur with another study, in which older women view pregnancy as a normal event rather than a medical condition requiring professional monitoring and supervision [23]. Contrary to our finding, Pell et al. reported that adolescents and unmarried younger women tend to hide their pregnancies and delayed ANC to avoid the potential social implications of pregnancy: exclusion from school, expulsion from their natal home, partner abandonment, stigmatization and gossip [24]. However, in our previous study we found no association between maternal age and ANC initiation at 1 st trimester, may be this could be explained by the fact that the study was carried out in a rural community [25].

In this study we found that parity influenced both early ANC initiation and having at least 4 ANC visits. The fewer the number of children a woman has the higher the probability of initiating ANC visit at 1 st trimester and having at least 4 ANC visits. This was also confirmed by our previous study which showed that probability of utilizing ANC increases with decrease in parity [25]. Pell, et al., argue that unaccustomed to the experience of pregnancy, the associated signs and symptoms, some primagravidae were more likely to seek advice and assistance and initiate ANC earlier [23,24]. Matsuoka, et al. also found that multiparous women who had experienced one or more healthy pregnancies view pregnancy as a normal event [23].

Generally, the women in the urban area use more ANC at high level health facilities than the rural women. This difference might be explained primarily by differences in the availability of health facilities between the two areas [26]. Results from this study also confirm this advantage; urban women had higher probability in initiating ANC at 1 st trimester and having at least 4 ANC visits compared to rural women. A study of two cohorts of pregnant women in Vietnam also showed that urban women had more visits and used more services than women in the rural areas [26]. The difference between the two areas in terms of time for the first visit was even larger than the frequency of ANC. The late attendance in ANC among the rural women was possibly due to women's lack of awareness about the importance of early use of ANC among women [26]. According to Abou-Zahr \& Wardlaw, there are marked urban/rural differentials in use of antenatal care, the differences being most pronounced for four or more antenatal visits [17]. Women living in urban areas are generally twice as likely as those living in rural areas to report four or more antenatal care visits [17]. In this study, only three regions were found to have significant association with early ANC initiation. Nairobi, Coast and Nyanza were found to have higher probability to early ANC initiation compared to North eastern province. May be this could be explained by Nairobi being the capital city of Kenya is well versed with infrastructure which could be a motivating factor for early initiation while Coast and Nyanza have numerous intervening nongovernmental organizations towards maternal health.

We also found that mothers from wealthier households had higher probability of initiating early ANC visit and having at least 4 plus ANC visits. This was similar to earlier finding which suggested that household wealth is positively associated with prenatal care use [27]. The explanation here is that wealthy households have the necessary resources to pay for the indirect costs of using prenatal care services. A study with similar findings in South Africa suggested that individuals of low SocioEconomic Status (SES) tend to reside in areas where they have decreased access to hospitals and the hospital infrastructure is inadequate and under-resourced [28]. Additionally, qualitative insights from a study done in rural South Africa found that low SES women did not perceive many hazards to pregnancy; rather the greatest perceived risks happened during labor and childbirth. One ANC visit was deemed as sufficient and was used primarily to obtain an antenatal attendance card which was required to give birth in a hospital [29].

Education had a positive influence to both early ANC visit initiation and at least 4 ANC visits, mothers with higher education had higher probability of early ANC visit initiation and at least 4 ANC visits. The reason could be that education enables the mothers to be aware of the benefits of prenatal care. Ribeiro et al. observed that low maternal schooling is associated with inadequate prenatal care use [30]. Use of public media sources like listening radio, watching television and reading newspapers increases the awareness of people on health and other matters. In this study, use of these public media sources significantly influenced the use of ANC services. Women who watch television or read newspaper/magazine more frequently had higher probability of initiating ANC visit in the 1 st trimester and have at least 4 ANC visits, while those listening to radio frequently had higher probability of initiating ANC visit at 1 st trimester compared to those who don't at all. A study in Nigeria has also shown that community media saturation was found to be a strong predictor of maternal health service utilization [31].

Our study shows that a handful of women sought ANC services in government health center or dispensary which are geographically accessible to most rural communities in Kenya, while a third of women sought ANC services in the government hospital, and only 1 in every 5 women used either private or faith based health facility. This study assessed all ANC services recommended for uncomplicated 
pregnant women. The results show that the use of ANC services was still poor, nearly a third of women did not receive simple and cost effective assessments such as weight, height and blood pressure measurement or urine test and then might miss the opportunity to detect early pregnancy conditions like pre-eclampsia [32]. Health education is one of the essential components of an ANC visit and the low proportion of women who received health education on complications during pregnancy in this study indicates poor communication between health workers and women. Some of the preventive measures such as iron-folate supplementation, tetanus toxoid and presumptive/preventive treatment for malaria with SP showed coverage gap existing. We also demonstrate that variability in provision of ANC service content exist among various types of health facility. We found that women who sought ANC service in the private health facility, faith based health facility and government hospital had higher probability of their weight measured, height measured, blood pressure taken, urine sample taken, advised on complication during pregnancy and given tetanus injection. This put women attending government health centers and dispensaries at risk of not receiving the required ANC services as recommended by WHO.

\section{Conclusion}

Both ANC initiation and at least 4 ANC visits varied with maternal age, region of residence, urban residence, wealth index, education and the form of media. A handful of women sought ANC services either in government health centers or dispensaries which did not provide adequate ANC service contents as recommended by WHO. This may explain the reason why use of ANC services were still poor, as about third of women did not receive simple and cost effective assessments such as weight, height and blood pressure measurement or urine test and then might miss the opportunity to detect early pregnancy conditions like pre-eclampsia The low proportion of women who received health consultations in this study indicates poor communication between health workers and women. Some of the preventive measures such as iron-folate supplementation, tetanus toxoid and presumptive/preventive treatment for malaria with SP showed coverage gap existing.

\section{Recommendations}

With the free maternal health care provision in Kenya, government efforts should be designed to improve on supplies to government health facilities especially at health centers and dispensaries level which serve more than half the population of pregnant women. In addition, location disparities should be eliminated by outreach village clinics that should be well stocked with the requirements of a successful antenatal care. Government policy should help to increase media penetration amongst the masses and sensitize mothers on the importance of initiating the first visit early enough and also on the frequency of visits for a maximum uptake of the care content. There is need to assess the quality health education provided at ANC visits in order to have an insight of the gap existing.

\section{References}

[1] WHO, Maternal and Child Health Fact Sheet. 2012. http://www.who.int/mediacentre/factsheets/fs348/en/.

[2] UNFPA, 2013 Fact Sheet. 2013. http://www.unfpa.org/public/home/mothers/pid/4381.

[3] UN, The Millennium Development Goals Report 2012. 2012, New York: United Nations.

[4] AUC, UN. Report on Progress in Achieving the Millennium Development Goals in Africa, 2013. in Abidjan: Côte d'Ivoire Meeting of the Committee of Experts of the Sixth Joint Annual Meetings of the ECA Conference of African Ministers of Finance, Planning and Economic Development and AU Conference of Ministers of Economy and Finance. 2012. Abidjan, Côte d'Ivoire: United Nations Economic and Social Council, Economic Commission for Africa \& African Union Comission.

[5] WHO, UNFPA \& UNICEF, Trends in maternal mortality 1990-2010. 2012, WHO: Geneva, Switzerland.

[6] Kenya National Bureau of Statistics (KNBS), Kenya Demographic and Health Survey 2008-09. 2010, Calverton, MD, USA: KNBS and ICF International.

[7] UNICEF, State of the Worlds children 2006. 2006, New York: United Nations Children's Fund.

[8] Koblinsky M., Mathews Z., Hussein J., The Lancet Maternal Survival Series steering group: Maternal Survival 3: Going to scale with professional skilled care. Lancet, 2006(368): p. 1377-1386.

[9] AbouZahr C., Wardlaw T., Maternal mortality at the end of a decade: signs of progress? Bulletin of the World Health Organisation, 2001. 6(79): p. 561-568.

[10] Urassa D.P., Carlstedt A., Nystrom L., Quality assessment of the antenatal program for anaemia in rural Tanzania. International Journal for Quality Health Care, 2002(14): p. 441-448.

[11] Mattar C.N., Chong Y.S. Chew A., Simple antenatal preparation to improve breastfeeding practice: a randomized controlled trial. 2007. p. 73-80.

[12] Campbell O.M.R., Graham W.J., The Lancet Maternal Survival Series steering group: Maternal survival 2: Strategies for reducing maternal mortality: getting on with what works. Lancet, 2006(368): p. 1284-99.

[13] Carroli G., Rooney C., Villar J., How effective is antenatal care in preventing maternal mortality and serious morbidity? An overview of the evidence. Paediatr Perinat Epidemiol, 2001. 1(15): p. 1-42.

[14] Haws R.A., Thomas A.L., Bhutta Z., Impact of packaged interventions on neonatal health: a review of the evidence. Health Policy and Planning, 2007(22): p. 193-215.

[15] WHO \& UNICEF, Antenatal Care in developing Countries: Promises, Achievements and Missed Opportunities: An Analysis of Trends, Levels, and Differentials: 1990-2001. 2003, Geneva, New York: WHO \& UNICEF.

[16] Villar J, Ba A.H.P., WHO Antenatal Care Randomized Trial: Manual for the Implementation of the New Model. 2002, Geneva: WHO.

[17] Abou-Zahr CL, Wardlaw T., Antenatal care in developing countries: Promises achievements and missed opportunities: An analysis of trends, level and differentials, 1990-2001. 2003, Geneva: WHO and UNICEF.

[18] Kiwuwa M.S., Mufubenga P., Use of antenatal care, maternity services, intermittent presumptive treatment and insecticide treated bed nets by pregnant women in Luwero district, Uganda. Malaria Journal, 2008(7): p. 44

[19] Magadi M.A., Madise N.J., Rodrigues R.N., Frequency and timing of antenatal care in Kenya: explaining the variations between women of different communities. Soc Sci Med, 2000(51): p. 551-561.

[20] Ndidi E.P., OseremenI. G., Reasons given by pregnant women for late initiation of antenatal care in the niger delta, Nigeria. Ghana Med J, 2010(44): p. 47-51.

[21] Central Bureau Of Statistics (CBS) M.O.H. and ORC Macro, Kenya Demographic and Health Survey 2003. 2004, Calverton, MD, USA: CBS, $\mathrm{MOH}$, and ORC Macro.

[22] Division, Maternal and Child Health, Focused Antenatal Care: Providing integrated, individualized care during pregancy. 2007, 
Office of Health, Infectious DIseases and Nutrition, Bureau for Global Health U.S. Agency for International Development.

[23] Matsuoka S, Aiga H., Rasmey L.C., Perceived barriers to utilization of maternal health services in rural Cambodia. Health Policy, 2010(95): p. 255-263.

[24] Pell C., Men Aca A. Were, Factors Affecting Antenatal Care Attendance: Results from Qualitative Studies in Ghana, Kenya and Malawi. PLoS ONE, 2013. 1(8): p. e53747.

[25] Asweto, C.O. Aluoch J.O.,Obonyo C.O., Ouma J.O., Maternal Autonomy, Distance to Health Care Facility and ANC Attendance: Findings from Madiany Division of Siaya County, Kenya. American Journal of Public Health Research, 2014. 2(4): p. 153-158.

[26] Toan K.T., Chuc T.K. Hinh N., Urban - Rural Disparities in Antenatal Care Utilization: a study of two cohorts of pregnant women in Vietnam. BMC Health Services Research, 2011(11): p. 120.

[27] Celik, Y. \& Hotchkiss D., socioeconomic determinants of maternal health care utilization in Turkey. Social Science Medicine, 2000. 12(50): p. 1797-1806.
[28] Nkonki L.L., Chopra M., Doherty T., Explaining household socioeconomic related child health inequalities using multiple methods in three diverse settings in South Africa. Int J Equity Health, 2011(10): p. 13.

[29] Myer L \& Harrison A., Why do women seek antenatal care late? Perspectives from rural South. Africa. J Midwifery Womens Health, 2003. 4(48): p. 268-272.

[30] Eleonora RO Ribeiro, Alzira M.D.N.G., Heloisa B., Danilo D.F.L., Maria L.D.A., Luiz de Souza, Antonio A.M.S., Ricardo Q.G., Risk factors for inadequate prenatal care use in the metropolitan area of Aracaju, Northeast Brazil. BMC Pregnancy and Childbirth, 2009. 31(9): p. 1-8

[31] Babalola S., Fatusi A., Determinants of use of maternal health services in Nigeria - looking beyond individual and household factors. BMC Pregnancy Childbirth, 2009(9): p. 43.

[32] Health-Evidence-Network, What is the effectiveness of antenatal care? 2005, Copenhagen: WHO Regional Office for Europe. 